\title{
What should we expect from innovation? A model-based assessment of the environmental and mitigation cost implications of climate-related $R \& D^{\text {t }}$
}

\author{
Valentina Bosetti ${ }^{\mathrm{a}, *}$, Carlo Carraro ${ }^{\mathrm{b}}$, Romain Duval ${ }^{\mathrm{c}}$, Massimo Tavoni ${ }^{\mathrm{d}}$ \\ a Fondazione Eni Enrico Mattei and CMCC, Italy \\ ${ }^{\mathrm{b}}$ Fondazione Eni Enrico Mattei, University of Venice, CEPR, CESifo and CMCC, Italy \\ c OECD Economics Department, France \\ d Fondazione Eni Enrico Mattei, Princeton Environmental Institute and CMCC, Italy
}

\section{A R T I C L E I N F O}

\section{Article history:}

Received 9 March 2010

Received in revised form 11 February 2011

Accepted 16 February 2011

Available online 5 March 2011

\section{JEL classification:}

$\mathrm{HO}$

H3

H4

Q32

Keywords:

Climate change

Environmental policy

Energy R\&D fund

Stabilization costs

\begin{abstract}
A B S T R A C T
This paper addresses two basic issues related to technological innovation and climate stabilization objectives: can innovation policies be effective in stabilizing climate? To what extent can innovation policies complement carbon pricing (taxes or permit trading) and improve the economic efficiency of a mitigation policy package? To answer these questions, we use an integrated assessment model with multiple externalities and an endogenous representation of the technical progress in the energy sector. We evaluate a range of innovation policies, both as stand-alone and in combination with other mitigation policies. Our analysis indicates that innovation policies alone are unlikely to stabilize global concentration and temperature. As for the benefits of combining climate and innovation policies, we find efficiency gains of 10\% (6 USD Trillions in net present value terms) for a stringent climate policy, and 30\% (3 USD Trillions) for a milder one. However, such gains are reduced when more plausible (sub-optimal) global innovation policy arrangements are considered.
\end{abstract}

(c) 2011 Elsevier B.V. All rights reserved.

\section{Introduction}

The issue of the role and potential effectiveness of technological change for mitigating climate change has gained momentum in both the literature and the political debate over the past decade. Despite the many uncertainties around the magnitude of the impacts of technological change on mitigation costs, there is now broad agreement that innovation will be required to foster the needed decarbonisation of the economy. Furthermore, in the presence of both environmental and innovation externalities, the optimal set of climate policy instruments should include explicit R\&D and possibly technology diffusion policies, in addition to carbon pricing policies that stimulate new technology purely as a side effect of internalising the environmental externality (Jaffe et al., 2005; Bennear and

\footnotetext{
is This paper is part of the research work being carried out by the Sustainable Development Programme of the Fondazione Eni Enrico Mattei. The authors are grateful to OECD for financial support. The views expressed in this paper are those of the authors, and do not necessarily reflect those of the OECD.

* Corresponding author at: FEEM, Cso Magenta 63 20123, Milano, Italy. Tel.: + 39 0252036983; fax: + 390252036946 .

E-mail address: Valentina.bosetti@feem.it (V. Bosetti).
}

Stavins, 2007). On the other hand, relying on R\&D alone might be not sufficient to achieve stringent targets and/or to minimise mitigation costs, because such an approach would provide no direct incentives for the adoption of new technologies and, by focusing on the long term, would miss near-term opportunities for cost-effective emissions reductions (Philibert, 2003; Sandén and Azar, 2005; Fisher, 2008).

Against this background, innovation and technology policies have received considerable attention from policy makers in the past few years. Proposals of international technology agreements have been put forward, that would encompass domestic and international policies to foster R\&D and knowledge-sharing (Newell, 2008). Innovation strategies have also been analysed in the context of climate coalition formation, suggesting that they are indispensable for improving the robustness of international agreements to control climate change (Barrett, 2003). On the policy side, some climaterelated scientific and technology agreements have emerged, including the Carbon Sequestration Leadership Forum, the Asia Pacific Partnership on Clean Development and Climate, and the International Partnership for a Hydrogen Economy. Most recently, the accord signed in Copenhagen at COP15 envisages a network of "Climate Innovation Centres" to facilitate collaboration on clean technologies between developed and developing nations. 
Despite the growing interest for climate-related technological change, there is so far limited quantitative evidence on the role that innovation policies should play in a climate stabilisation policy package, as well as on the particular R\&D areas that should be targeted. Popp (2006) has shown that combining carbon pricing and R\&D policies can yield welfare gains, but that these are modest with respect to the optimal carbon tax case. Fischer and Newell (2008) find that an optimal portfolio of policies that includes, among others, emissions pricing and R\&D can achieve significant efficiency gains.

Energy-economy-climate models used to evaluate mitigation policies have incorporated innovation mechanisms such as R\&D investments only to a limited extent. This is a drawback, since the optimal policy mix is likely to depend on the returns to scale of energy technologies that are subject to learning (Gerlagh and van der Zwaan, 2006), and that are determined by the evolution of the whole energy system. Also, the limited analysis available of R\&D investments required to comply with climate stabilisation objectives (Schock et al., 1999; Davis and Owens, 2003; Nemet and Kammen, 2007) has been carried out mostly outside the realm of general equilibrium models. The main objective of this paper is to bring innovative input to the debate on the role of technology policy for climate change mitigation, focusing on the interplay between innovation and carbon pricing policies using the rich set-up allowed by integrated assessment models. To this end, we investigate several potential intervention strategies, with technology policies being used either as a substitute or as a complement to carbon pricing.

The rest of this paper is organised as follows. Section 2 provides a brief overview of the model used in this paper, WITCH, focusing on the various channels of endogenous technological change featured in the model and the types of innovation policies that can be assessed. Section 3 looks at the climate effectiveness of innovation policies, i.e. at the extent to which such policies alone can bring about emission reductions. Section 4 then turns to the economic effectiveness of innovation policies, i.e. the extent to which they can lower the economic costs of a climate policy package aimed at meeting a given climate change mitigation target. We assess the potential economic efficiency gains from hybrid innovation/carbon pricing policies relative to a pure carbon-pricing approach, and compare these potential efficiency gains to those achievable in practice when considering politically more realistic - but sub - optimal - policy combinations. Section 5 concludes the paper by summarising its main results.

\section{Endogenous technological change and innovation policy options in WITCH}

The analysis presented in the paper is carried out using the World Induced Technical Change Hybrid (WITCH) model, an energyeconomy-climate model developed by the climate change group at FEEM. The model has been used extensively for economic analysis of climate change policies. ${ }^{1}$

WITCH is a computable macro-economic model with an in-built representation of the energy sector, thus belonging to the class of fully integrated (hard link) hybrid models. The economy follows an optimal growth model in which the regions that populate the world (12 macro-regions in the present paper) maximize welfare measured as a function of consumption - intertemporally over a long horizon (the model is run here until 2150). ${ }^{2}$ The model tracks

\footnotetext{
1 See www.witchmodel.org for a list of applications and papers.

2 The dynamic nature of the model naturally raises the question of the choice of the discount rate. In the model, the social time preference starts at $3 \%$, declining over time. However, since most of the analysis is undertaken in a cost-effective framework rather than a cost-benefit one, the effect of discounting on results is negligible.
}

investments and expenditures for the main carbon mitigation technologies and carriers, selecting the portfolio which is dynamically optimal given perfect foresight. Production is represented via nested constant elasticity of substitution functions, which allows to track the greenhouse gas emissions generated by burning fossil fuels or by using land. A simplified climate model computes the greenhouse gas radiative forcing associated with these emissions. Additional model description can be found in the Appendix to this paper.

WITCH has two main distinguishing features that are especially relevant in the context of the present analysis. The first one is a representation of endogenous technical change in the energy sector. Advancements in a range of carbon mitigation technologies are described by both innovation and diffusion processes. Learning-byResearching (LbR) and Learning-by-Doing (LbD) shape the optimal $\mathrm{R} \& \mathrm{D}$ and technology deployment responses to given climate policies. Specifically, the investment costs of renewable power generation and breakthrough low-carbon technologies are lowered by investments in dedicated R\&D and technology deployment via a two-factor learning curve (see Appendix). R\&D investments also increase the energy efficiency of the overall production function by contributing to the accumulation of knowledge capital that substitutes for energy demand.

In terms of innovation market failures, energy-related knowledge in a country depends not only on the country's own R\&D investments but also on those made by others, via international spillovers. For a given region, the magnitude of such spillovers depends on the distance of its R\&D knowledge stock (cumulative past R\&D) to the frontier, but also on its absorptive capacity which depends positively on its knowledge stock. This gives rise to a bell-shaped relationship between a country's R\&D knowledge stock and spillovers, with the latter being lowest when the former is either very low (weak absorptive capacity) or very high (small distance to technological frontier) (for details, see Bosetti et al., 2008 and the Appendix of this paper). In turn, these international $R \& D$ spillovers provide a case for international R\&D policies.

WITCH accounts for higher social returns from R\&D by calibrating a higher marginal price of capital but on the other hand assumes an exogenous crowding out of other forms of R\&D. Thus, the implications of biased technical change are not considered here, but they have been evaluated in applications of WITCH on the direction and pace of technical progress (Carraro et al., 2009a) and on human capital formation (Carraro et al., 2009b). Nevertheless, it should be noted that important additional R\&D externalities, such as appropriability and knowledge protection issues, are not captured due to the aggregated structure of the model.

The second relevant modelling feature is the game-theoretic set up. WITCH is able to produce two different solutions. The first is the socalled globally optimal solution, which assumes that countries fully cooperate on global externalities. This is achieved by jointly optimizing the global welfare (using Negishi weights to equalize marginal utilities across regions). The second type of solution is a decentralised one that is strategically optimal for each given region (or coalition of regions) in response to all other regions' choices, and corresponds to a Nash equilibrium. This is achieved through an iteration procedures in which each region (or coalition of regions) maximizes its own welfare, taken as given global variables which are computed offline the optimization. This modelling feature allows accounting for externalities due to all global public goods $\left(\mathrm{CO}_{2}\right.$, international knowledge spillovers, energy markets, etc....), making it possible to model free-riding incentives and to internalize one or more externality. This allows exploring the potential interactions between different policies aimed at internalising the technological externality and/or the climate externality.

Three types of R\&D policies summarised in Table 1 are considered in this paper, which differ in the type of R\&D they subsidise: 
i) Energy efficiency enhancing RED investments (E.E.). The model assumes that an energy efficiency capital stock can be built through dedicated R\&D investments, which is a substitute for physical energy (via a constant elasticity of substitution production function) in producing final energy demand.

ii) Wind, solar and Carbon Capture and Storage RED investments $(W+S$ E CCS). The productivity of wind, solar and CCS can be decreased by R\&D investments, through a learning curve formulation for which every given relative increase in the knowledge capital translates into a constant decrease in investment costs.

iii) Breakthrough technologies RED investments (Advanced Techs). As with wind, solar and CCS, R\&D decreases the cost of two non-commercial, advanced carbon-free technologies. These technologies can substitute for existing ones in the electricity and non-electricity sectors, respectively.

It is important to emphasize that there exists considerable uncertainty surrounding the appropriate way of modelling and calibrating the drivers of technological change. In essence, there is both specification and parameter uncertainty. Specification uncertainty relates in particular to the modelling of R\&D returns. The issue of whether aggregate marginal returns to $R \& D$ are decreasing or constant or even increasing is still being debated in the growth literature. In WITCH, all three types of R\&D expenditures mentioned above display decreasing marginal returns. This is consistent with available empirical evidence for low-carbon technologies such as wind and solar power as well as for energy-saving innovation in the United States (Popp, 2002). Diminishing returns to R\&D in reducing the costs of clean technologies is also justified by the fact that these technologies (including renewable) rely on inputs, such as raw materials or human capital, whose supply costs are constant or even increase in deployment. These scarcities limit the ability of R\&D to keep increasing the efficiency of clean energy capital. Regarding parameter uncertainty, in previous analysis (Bosetti et al., 2009b), we have performed extensive sensitivity analysis on the key parameters, both on those regulating diffusion and innovation. The main finding of that assessment, which is still relevant for the analysis of this paper, is that essentially only the specification of backstop technologies has a significant bearing on projected carbon prices and mitigation policy costs.

With this tool in hand, we aspire to assess the three types of innovation policies described in Table 1 in terms of both their potential carbon emission abatement potential if used as stand-alone policies, and the economic efficiency gains they can generate when combined with an explicit climate stabilisation policy.

\section{Climate effectiveness of innovation policies}

We start by analysing the environmental effectiveness of standalone innovation policies, looking at their impact on carbon emission and concentration trajectories over the century. We simulate innovation policies assuming global R\&D funds of various sizes are used to subsidize the three categories of Table 1 . As a central value, we use a fund size equal to $0.08 \%$ of Global World Product (GWP). This share is consistent with the optimal R\&D investments needed to comply with a stringent climate stabilisation policy in the WITCH model (Bosetti et al., 2009a), and is in line with the peak level of public energy R\&D expenditures achieved across the OECD area in the early 1980s. Similar values have also been suggested in other recent

Table 1

The three types of innovation policies considered in this paper.

\begin{tabular}{ll}
\hline Acronym & Innovation policy features \\
\hline E.E. & R\&D for energy efficiency enhancement \\
$W+S$ and CCS & R\&D to improve productivity of wind, solar and CCS \\
Advanced techs & R\&D for advanced, breakthrough technologies \\
\hline
\end{tabular}

analyses (IEA, 2008, 2010). For robustness check, and in order to assess the maximum world emission reduction that could be achieved through a stand-alone innovation policy, we pursue additional experiments with incrementally larger funds amounting to up to $2 \%$ of GWP. The international R\&D fund is assumed to be financed by contributions from OECD regions that are proportional to their GDP. In turn, each world region receives from the international R\&D fund a subsidy which adds to its own regional R\&D investments in innovation. The fund is distributed across regions on an equal per capita basis, although alternative distribution rules were also tested to check for robustness.

Figs. 1 and 2 report $\mathrm{CO}_{2}$ emissions and concentrations for the 4 innovation policies, as well as for the reference (BAU, no policy) and a climate stabilisation pathway at $450 \mathrm{CO}_{2}$ (about $535 \mathrm{CO} 2-\mathrm{e}$ ) ppmv. The main result is that all innovation policies fall short of generating the mitigation action needed to stabilise carbon concentrations. In all cases, the atmospheric stock of $\mathrm{CO}_{2}$ keeps increasing and so does the global temperature, which remains rather close to the baseline case.

There are differences across innovation policies, however. The "Advanced Techs" R\&D policy, under which two advanced technologies become competitive via R\&D investments, yields the higher mitigation and manages to stabilise carbon emissions - albeit not concentrations. Given the improvements needed and commercialisation lags, these technologies become effectively available around mid-century, leading to some emission reductions afterwards. The " $W+S$ \& CCS" R\&D policy achieves somewhat smaller reductions relative to BAU, and with a different time profile. Unlike new breakthrough technologies, wind, solar and CCS can quickly penetrate the market if supported by R\&D subsidies, allowing some emission reductions during the first half of the century.

However, in the long term returns to R\&D investments in both technologies are somewhat counteracted by the costs due to intermittency (for Wind and Solar) and storage repository (for CCS). The last option, namely R\&D dedicated to energy efficiency (E.E.), is almost ineffective for two reasons. First, some decline in energy intensity is already embedded in baseline scenarios, consistent with the dynamics of the last 50 years. As a consequence, achieving additional energy efficiency improvements via R\&D is fairly expensive at the margin. Second, efforts to decarbonise the economy will ultimately be crucial to make a dent in emissions. This cannot be achieved through improvements in energy efficiency alone, and rather requires the progressive phasing-out of fossil-fuel-based energy technologies.

While the above simulations assume sizeable R\&D spending, roughly four times higher than current public energy-related

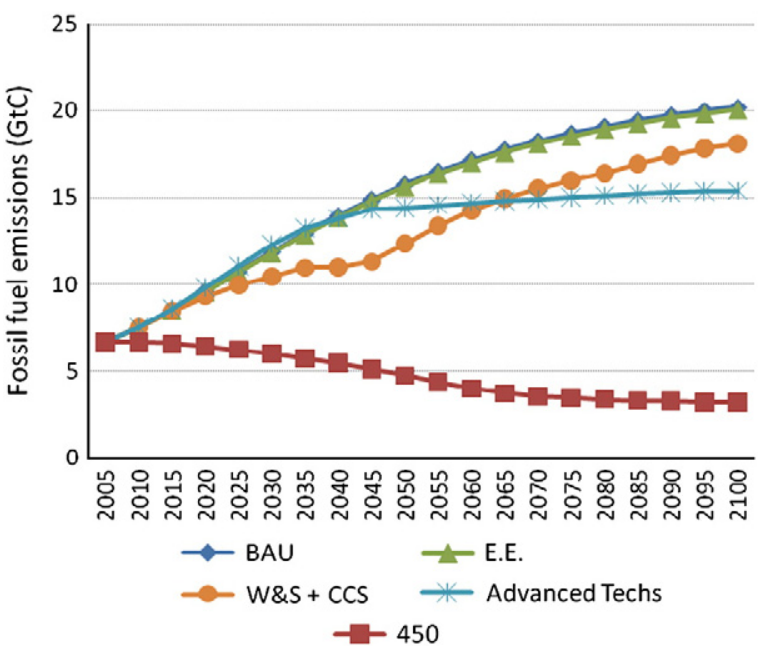

Fig. 1. Fossil fuel emission paths under alternative innovation policies, compared with emission paths in the baseline and $450 \mathrm{ppm} \mathrm{CO}_{2}$ only stabilisation cases. 


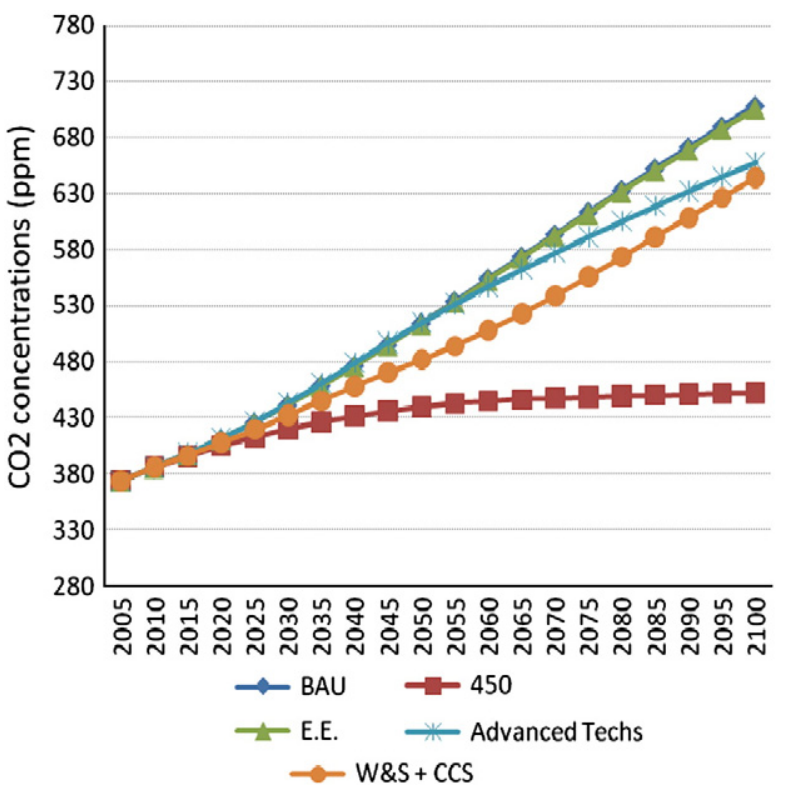

Fig. 2. $\mathrm{CO}_{2}$ concentration paths under alternative innovation policies, compared with emission paths in the baseline and $450 \mathrm{ppm} \mathrm{CO}_{2}$ only stabilisation cases.

expenditures, one open question is whether even higher spending might overturn our conclusions. Likewise, mixed strategies combining all three types of R\&D could in principle deliver higher returns, especially since alternative options differ in the time profile and longrun potential of the emission reductions they can achieve. We have therefore carried out a number of sensitivity analyses, varying the size and allocation of the technology fund. A very robust finding across all simulations is that the largest achievable reduction in emissions with respect to the baseline is in the order of $13 \%-14 \%$ in cumulated terms throughout the century, in the range of the "Advanced Techs" case discussed above. In particular, while a larger international R\&D fund induces larger emission reductions over the medium term, its longterm impact is limited by declining marginal returns to R\&D, as well as to a lesser extent by the positive counteracting impact of the fund on world GDP and emissions.

This is illustrated in Fig. 3 through a comparison between two funds amounting to $2 \%$ of GWP and $0.2 \%$ respectively, both of which are assumed to subsidise equally all three types of R\&D. Although the larger fund implies lower emissions in the medium term, by the end of the century the two innovation policies result in similar and growing

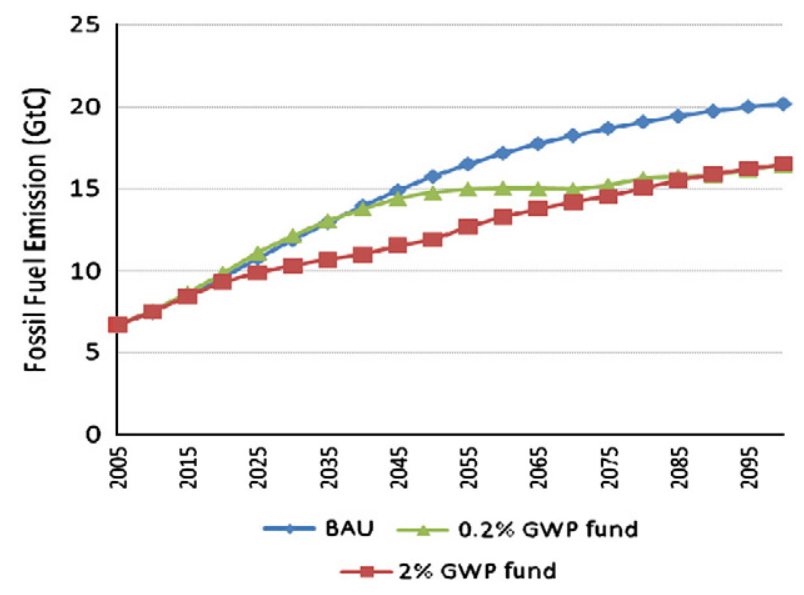

Fig. 3. Fossil fuel emission paths for different sizes of a mixed innovation policy.

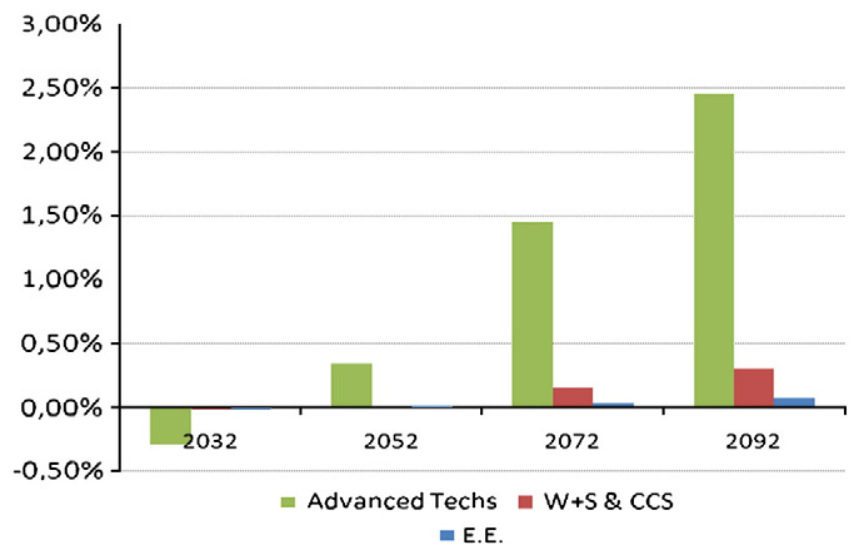

Fig. 4. Economic benefits (\% difference of global consumption with BAU) of stand-alone innovation policies, for an R\&D fund equal to $0.08 \%$ of GWP.

emissions, due to the reallocation of consumption from earlier to later periods in time. Furthermore, the medium-term impact of a large R\&D fund is insufficient to put world emissions, even for the first few decades, on a path consistent with long-run stabilisation of carbon concentrations at safe levels. These results reflect to a good extent the assumption of diminishing returns to R\&D already discussed above. Moreover, rebound effects are also at play, with the increased productivity fostering more growth and thus energy demand, not all of which can be met by clean sources.

\section{Economic efficiency gains from hybrid innovation/carbon pricing policies}

Although the simulation results from the previous section clearly point to the lack of environmental effectiveness of R\&D as a standalone policy, R\&D may still contribute to reducing the cost of a climate policy package when used as a complement to carbon pricing policies. The main reason is illustrated in Fig. 4, which shows the economic gains from a fund amounting to $0.08 \%$ of GWP used as a stand-alone policy. By internalising international technological externalities and forcing higher innovation investments in earlier periods, innovation policies deliver some welfare gains during the second half of the century, at the expenses of initial losses. While these gains are small under the "W+S \& CCS" and "EE" innovation policies, they are sizeable in the "Advanced Techs" case, which as discussed before also achieves the largest emission reductions. Thus, R\&D programs meant to facilitate the development of breakthrough technologies that can help decarbonise sectors such as transport appear to hold the largest emission-reduction and cost-reduction potential.

It should be noted, however, that such policies still impose an economic cost in the first decades of the century, albeit a fairly small one in this case. Funds of larger sizes generate higher early penalties; for example, a fund of $2 \%$ of GWP as shown in Fig. 3 would yield consumption losses of 2 to 3\% and benefits only after 2060 .

The next sections assess the economic efficiency gains from hybrid carbon pricing/innovation policies in two steps. In a first step, we illustrate the innovation effects and economic impacts of a world carbon price alone under a 450 ppm $\mathrm{CO}_{2}$ only (535 $\mathrm{CO} 2$ eq) carbon concentration stabilisation target. ${ }^{3}$ In a second step, we estimate the

\footnotetext{
${ }^{3}$ We assume the existence of an international carbon market that equalizes marginal abatement costs. Emission allowances are allocated on an equal per capita basis.
} 


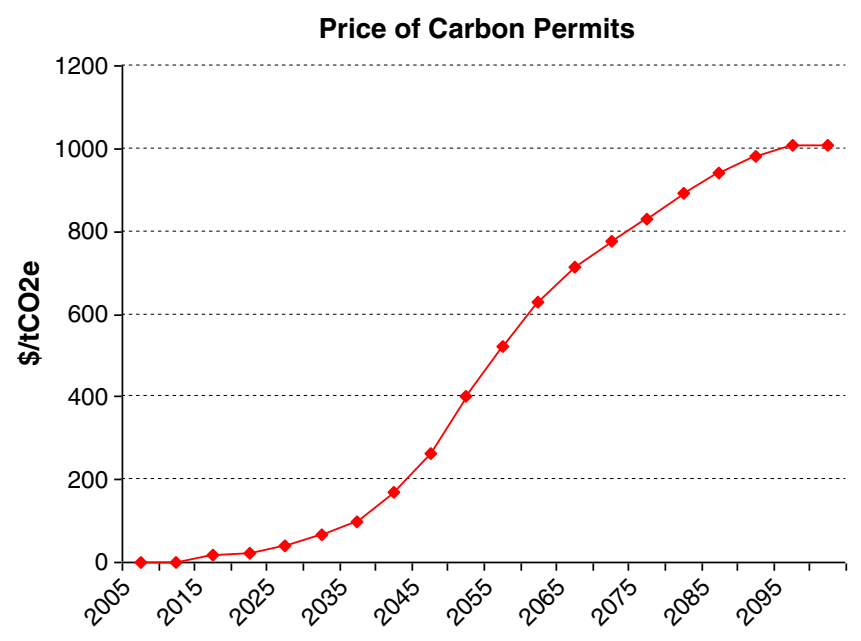

Fig. 5. The price path of $\mathrm{CO} 2$ in the 450 ppm CO C $\left._{2} 535 \mathrm{ppm} \mathrm{CO}_{2} \mathrm{eq}\right)$ climate stabilization policy.

economic gains from incorporating an R\&D policy on top of that world carbon price.

\subsection{Innovation and economic costs under a climate stabilisation policy alone}

We begin by analysing the optimal investments in innovation when a stringent climate stabilisation policy is considered. ${ }^{4}$ A policy of this kind, although probably not sufficient to maintain the global temperature increase below the $2^{\circ}$ Celsius threshold, does require an immediate and rapid decarbonisation trajectory, for which currently available mitigation options need to be supplemented with innovation in low carbon technologies, especially in the transportation sector. The resulting carbon price path is shown in Fig. 5. The marginal cost of $\mathrm{CO} 2$ increases throughout the century with the stringency of the emission cuts, and is shown to be rather high in the second half of the century.

The prospect of high carbon prices induces significant increases in R\&D. For example, as shown in Fig. 6, public R\&D expenditures are found to quadruple with respect to baseline and, as a share of GDP, to approach the peak levels of the early 1980s. Most of the R\&D undertaken is dedicated to the two backstop technologies, i.e. to decarbonisation to both electricity and non-electricity, while R\&D dedicated to energy efficiency improvements is comparatively smaller.

Similar level of investments and their repartition have been recently suggested by other studies using different (mostly bottomup) approaches (IEA, 2009, 2010). These results depend on the specification of the R\&D process, which as noted before has been calibrated on empirical data. However, given the uncertainty regarding the effectiveness of the R\&D process across technologies, we have also performed some sensitivity analysis to test the robustness of the R\&D investment path to the learning rates of the breakthrough R\&Ds (which are the most important ones). Fig. 7 shows the R\&D investments for the central learning case, contrasted with a high and low cases. The high learning rate has been set at $18 \%$, which represents the highest rate observed in the literature for the case of combined cycle gas turbines during the 1980s (Jamasab, 2007). The lowest rate was set at $8 \%$, to ensure a mean preserving spread around the central case (set at 13\%). Results indicate that upward trends in energy R\&D are optimally induced by the climate policy

\footnotetext{
${ }^{4}$ We thus assume global cooperation in an international climate agreement, thus abstracting from issues such as international carbon leakage or supply side response from oil producers.
}

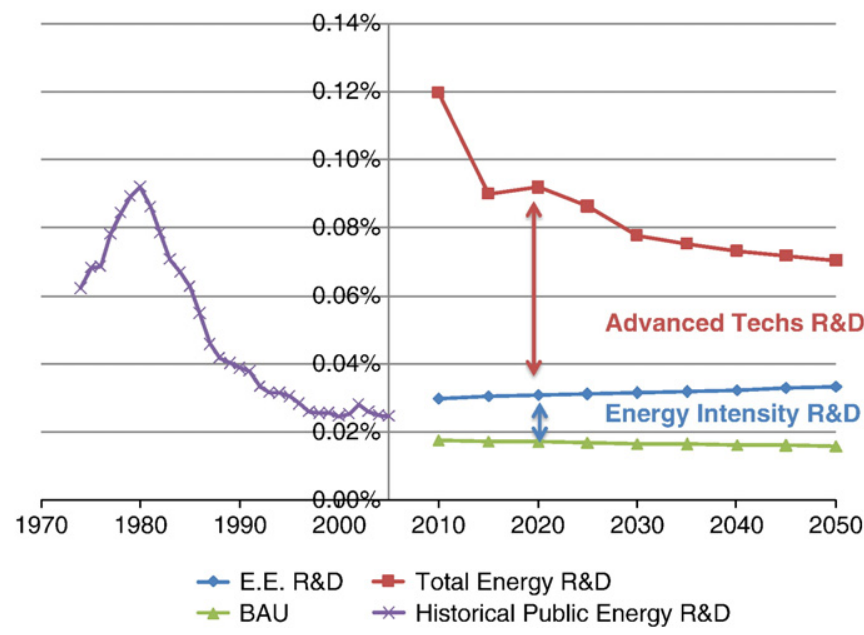

Fig. 6. Energy R\&D investments (as shares of GWP) in the baseline and the $450 \mathrm{ppm} \mathrm{CO}_{2}$ $\left(535 \mathrm{ppm} \mathrm{CO}_{2} \mathrm{eq}\right.$ ) concentration stabilisation policy alone, compared with historical figures.

irrespective of the magnitude of the learning rate, though differences can be observed in the timing of the investment profile. In particular, when the productivity of R\&D is higher, investments are anticipated, but eventually fall to lower levels, thanks to the higher effectiveness of the innovation. The opposite behaviour is observed for the low learning rate case, in which investments are deterred by roughly 10 year, but are eventually increased to make up for the lower effectiveness of R\&D.

The observed response of R\&D and technological change to carbon pricing, in particular the emergence of the advanced technologies, plays a major role in containing the costs of a climate stabilisation policy. This is illustrated in Fig. 8, which compares the costs of the climate policy under alternative assumptions regarding investment possibilities in advanced technologies. One extreme scenario assumes that the possibility to invest in such breakthrough technologies is foregone altogether, while an intermediate scenario assumes that R\&D investment is still possible in the non-electricity technology. Allowing R\&D investments in the advanced technologies greatly reduces mitigation costs at distant horizons, especially beyond midcentury, at the cost of higher losses in the first decades, due to the large increase in R\&D effort needed to bring about the breakthroughs. A strong carbon price signal would still be needed in the short term (in the order of $100 \$ / \mathrm{tCO}_{2}$ in 2030) to foster the large investments

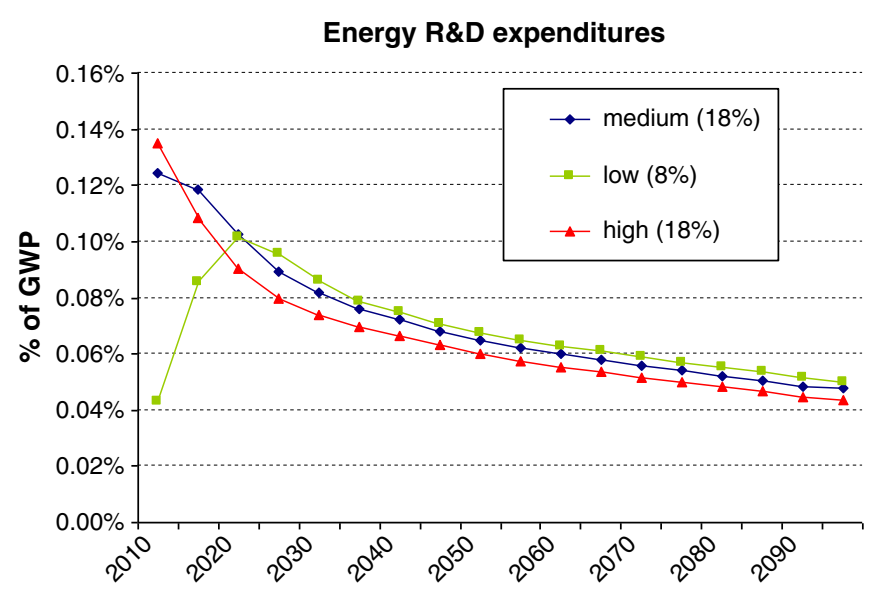

Fig. 7. Energy R\&D investments (as shares of GWP) in the $450 \mathrm{ppm} \mathrm{CO}_{2}$ (535 ppm $\mathrm{CO}_{2} \mathrm{eq}$ ) for 3 different learning rates for breakthrough R\&D. 


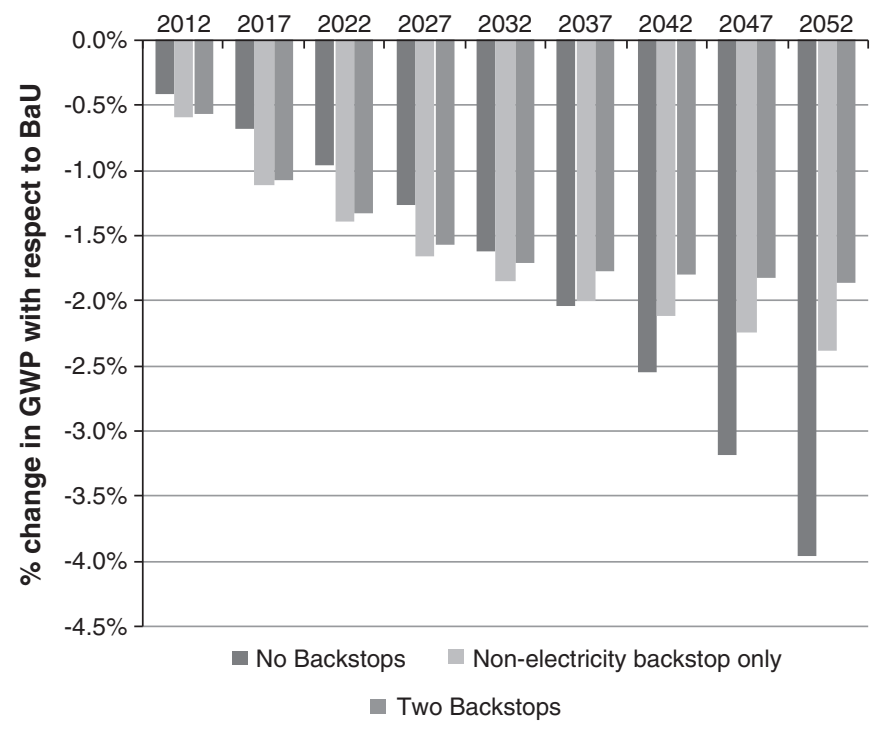

Fig. 8. Costs (\% GWP difference with $\mathrm{BAU}$ ) of a $450 \mathrm{ppm} \mathrm{CO}_{2}\left(550 \mathrm{ppm} \mathrm{CO}_{2} \mathrm{eq}\right)$ concentration stabilisation policy under alternative assumptions regarding investment possibilities in advanced technologies.

needed in both the available abatement opportunities and in the advanced technology R\&D programs.

The development of carbon-free technologies is especially important in the non-electricity sector, where the marginal costs of abatement are particularly high, a result which is also in line with bottom-up analysis (IEA, 2010). Compared with a scenario where R\&D investments can be made in both advanced technologies, a simulation where only the non-electricity carbon-free technology is available leads to a small increase in mitigation costs. These results highlight the importance of developing carbon-free technologies in the nonelectricity sector, notably in transport, where currently commercially available mitigation options have only limited abatement potential. Also, the electric sector already possesses a fairly rich technology portfolio needed to achieve a stringent climate target, provided that nuclear, CCS and renewables can be deployed on a sufficiently large scale. This lowers the gains at the margin from investing in new advanced technologies in that sector.

\subsection{Economic efficiency gains from optimal hybrid innovation/carbon pricing policies}

Having shown that a carbon pricing approach would already induce sizeable increases in overall R\&D spending, which as a result would significantly reduce mitigation costs, we now assess the economic efficiency gains of incorporating a global R\&D policy on top of the market based climate policy. From a policy standpoint, it is reasonable to expect that if countries are willing to cooperate on climate, they might also do so on innovation. However, these two types of cooperation are normally not assessed together, and in what follows our aim is to evaluate what benefits this joint strategy can accrue.

In order to do so, we compare two cooperative solutions of the WITCH model, namely one featuring cooperation on both climate and R\&D policies - i.e. combining a world carbon price and a global R\&D investment strategy that internalises all international knowledge spillovers - and another assuming cooperation on climate policy only - i.e. the climate stabilisation policy considered in Section 4.1 above, which implicitly assumes non-cooperative behaviour of each region in setting their R\&D spending.
Table 2

Investments in energy R\&D (billion USD, average 2010-2050) for the two cases with cooperation on only climate and on both climate and innovation. $450 \mathrm{CO} 2$ policy.

\begin{tabular}{lllc}
\hline & OECD & NON-OECD & WORLD \\
\hline Climate policy & 47.7 & 40.0 & 87.7 \\
Optimal policy & 49.3 & 46.3 & 95.6 \\
\% difference & $3 \%$ & $16 \%$ & $9 \%$ \\
\hline
\end{tabular}

Compared with cooperation on climate policy only, we find that an optimal policy with cooperation on both innovation and climate would yield somewhat higher energy R\&D expenditures. As shown in Table 2, on average global R\&D investments increase by about 9 billion USD a year, or $9 \%$. The largest increases occur in non-OECD countries: since these are far from the technological frontier, increased $R \& D$ spending enhances their ability to absorb the world knowledge pool. OECD countries also raise their innovation effort, although to a less extent, given their lower marginal returns to R\&D investments. The highest change occurs during the initial periods, up to 2020.

In economic terms, cooperation on both innovation and climate reduces the costs of climate mitigation, because it allows to internalize both the climate and innovation externalities. Global consumption losses overt the century (in net present value at 3\% discount rate) are reduced from $1.92 \%$ to $1.74 \%$, an efficiency gain of $10 \%$, or equivalently 6 trillion USD. These numbers confirm that combining carbon pricing and R\&D policies can yield welfare gains, but that carbon pricing alone could go a long way in determining the optimal investment portfolio consistent with climate stabilisation (Popp, 2006).

\subsection{Economic efficiency gains from realistic hybrid innovation/carbon pricing policies}

The $10 \%$ potential reduction in climate change mitigation costs from a global R\&D policy estimated in the previous version is largely theoretical. Indeed, while cooperation on climate change "merely" requires setting up a single world carbon price, in principle cooperation on $R \& D$ requires an omniscient world social planner that sets an optimal level of global R\&D and allocates it optimally across time, regions and types of R\&D. This is extremely unlikely to be achievable in the real world, and as such the $10 \%$ represents at best an upper bound. ${ }^{5}$

It is therefore instructive to assess the economic efficiency gain that could be achieved by a more plausible global R\&D policy, and to compare it with the maximum theoretical gain. To this end, we assume a global fund making a constant share of GWP, financed by OECD countries, allocated to each region on a per-capita basis, and spent only on breakthrough technologies, which we have shown have the largest cost-saving potential compared to alternatives. The results from such simulations in terms of efficiency gains carried out for a range of fund sizes are reported in Fig. 9.

Compared to the optimal global R\&D policy analysed in the previous paragraph, the "realistic" R\&D fund would have a smaller impact on mitigation policy costs, reducing the global cost of meeting the stabilisation target by at most 3-3.5\% relative to cooperation on climate policy only. This reduction in policy costs is found to be highest for a fund of about $0.07 \%$ of GWP, roughly in line with those

\footnotetext{
${ }^{5}$ Leaving aside the non-internalization of international R\&D spillovers when regions do not cooperate on innovation policy, $R \& D$ is set and allocated optimally in the model This assumes away domestic information, agency and political economy problems which make it difficult to select the good research programs and thereby reduce the value of $R \& D$ in practice. From that perspective the simulated gains from R\&D policies should be seen as an upper bound. At the same time and as noted above, however, it should be noted that the WITCH model's aggregate structure does not allow us to model issues related to private underinvestment in R\&D, which could in principle increase the efficiency gains deriving from R\&D policies.
} 


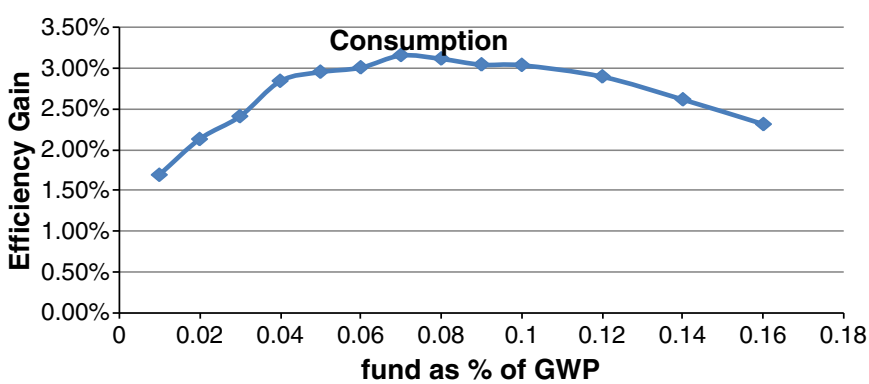

Fig. 9. Economic efficiency gains (\% difference in discounted consumption relative to cooperation on climate policy only) from a global R\&D fund dedicated to breakthrough technologies, under a $450 \mathrm{ppm} \mathrm{CO}_{2}\left(535 \mathrm{ppm} \mathrm{CO} \mathrm{CO}_{2} \mathrm{eq}\right)$ concentration stabilisation constraint and for different fund sizes.

analysed in the previous section of the paper. However, the gain is smaller than the one shown for the optimal case, given the different regional repartition. Higher spending is not found to be efficient due to decreasing marginal returns to R\&D. Overall, the small cost reduction achieved by the simple $R \& D$ fund compared with the maximum achievable savings highlights the importance of allocating spending optimally across time, regions and different types of R\&D.

\subsection{Economic efficiency gains from optimal hybrid innovation/carbon} pricing policies for a looser climate objective

Our results so far have indicated that innovation is a key ingredient to climate stabilisation, and that substantial investments in energyrelated $R \& D$ are needed to bring about the productivity changes required by low emission targets. As such, combining climate and innovation policies yields additional benefits, but those would be bounded by the high levels of investments already occurring in the climate scenarios. Indeed, our estimates have suggested that for a climate objective of $450 \mathrm{CO} 2$ only (535 CO2-eq) the efficiency gains of coupling innovation and climate policies would at best equal $10 \%$. However, the policy considered is a quite severe one, and one might wonder how results would change if a looser climate objective were considered.

As a final task, we investigate a milder climate objective of $550 \mathrm{CO} 2$ only (about $650 \mathrm{CO} 2$-eq) and again compare the case of cooperation on climate only with that of cooperation on both climate and innovation. Table 3 (the counterpart of Table 2) shows the R\&D investments in the two scenarios. Once again, the optimal policy implies more investments in R\&D than in the climate policy only. However, the global increase in investment is now in the order of $20 \%$, twice as much as under the more stringent climate objective, and also higher in levels ( +12.6 billions/yr), despite the fact that overall $R \& D$ investments are lower given the less ambitious climate target. The largest increase again occurs in developing countries, but developed ones also raise their investment levels.

In terms of macro-economic repercussions, the "full cooperation" and "climate cooperation only" set-ups yield consumption losses of $0.3 \%$ and $0.39 \%$, respectively. Thus, the relative efficiency gain is about $30 \%$, significantly higher than under the more stringent climate policy

Table 3

Investments in energy R\&D (billion USD, average 2010-2050) for the two policies with cooperation on only climate and on both climate and innovation. $550 \mathrm{CO} 2$ policy.

\begin{tabular}{lcll}
\hline & OECD & Non-OECD & World \\
\hline Climate policy & 35.2 & 29.4 & 64.6 \\
Optimal policy & 38.4 & 38.8 & 77.2 \\
$\%$ difference & $9 \%$ & $32 \%$ & $20 \%$ \\
\hline
\end{tabular}

scenario. In levels, however, the gains from coupling climate and innovation policies are twice as small under the less stringent target as under the more stringent one, specifically 3 trillion USD compared to 6 . The value of $R \& D$ in relative terms decreases with the stringency of the climate objective due to decreasing returns to innovation. However, since abatement costs are highly nonlinear, as exemplified by the steep path of carbon prices, the actual savings in dollar value from coupling climate and innovation policies are higher under more ambitious targets.

\section{Conclusion}

This paper has used WITCH, a global integrated assessment model featuring multiple externalities and endogenous technological change, to assess the potential for innovation policies to mitigate climate change or to lower the cost of doing so. Two main results stand out. First, innovation policies alone are unlikely to effectively control climate change. Even under large increases in global climaterelated $R \& D$ spending, emissions can be at best stabilised above current levels and $\mathrm{CO}_{2}$ concentration be reduced by about $50 \mathrm{ppm}$ relative to baseline by 2100 (from over $700 \mathrm{ppm}$ to about $650 \mathrm{ppm}$, or over $750 \mathrm{ppm} \mathrm{CO}_{2} \mathrm{eq}$ ). The decarbonisation of energy needed to meet stringent global emission reduction objectives has to be achieved at least partly by pricing carbon.

Second, relative to cooperation on emission reduction alone (through global carbon pricing), international cooperation on R\&D (through a global R\&D policy that would internalise international knowledge spillovers) might bring about additional benefits, of about $10 \%$ (or 6 USD Trillions) for a stringent climate policy and 30\% (or 3 USD Trillions) for a looser one. However, such an optimal global R\&D policy is difficult to achieve in practice, and under more realistic assumptions about the allocation of spending across time, countries and types of $R \& D$, the magnitude of efficiency gains are significantly reduced. This is because global carbon pricing alone is shown to have the potential to trigger substantial increases in R\&D expenditures, which implies that further spending under a global R\&D policy would run into decreasing marginal returns.

These findings are qualitatively robust to sensitivity analysis on key model parameters, notably returns to $R \& D$, learning rates and international knowledge spillovers in the various technological areas (see Bosetti et al., 2009b). At the same time, some limitations to our analysis should be acknowledged, which call for caution in interpreting our quantitative results. While assumed away in this paper, increasing returns to $R \& D$ cannot be fully ruled out, and the magnitude of international R\&D spillovers - a key justification for global policy intervention in climate-related R\&D - remains highly uncertain for lack of empirical evidence. Also, the model assumes away some domestic innovation failures that in practice might provide a stronger case for R\&D policy intervention than found in this paper - although it also ignores the information, agency and political economy problems that often undermine the effectiveness of public R\&D programs in practice. Such failures typically affect any type of innovation, but may be magnified in the area of climate change mitigation, such as appropriability problems (lack of credibility of intellectual property rights on key mitigation technologies that might emerge in the future), lack of credibility of carbon pricing policies (due to the impossibility for current governments to commit credibly to a future carbon price path), or failures specific to the electricity sector (network effects and thereby entry barriers associated with already installed infrastructure, cumulative nature of knowledge, ... etc.). It is however unclear whether the overall impact of credibility problems and lack of specific infrastructures would enhance or reduce R\&D investments (different effects have sometimes opposite signs) and therefore would increase or reduce the effectiveness of technical change on climate change control. Further research is needed to explore these issues. 


\section{Appendix A. Supplementary data}

Supplementary data to this article can be found online at doi:10.1016/j.eneco.2011.02.010.

\section{References}

Barrett, S., 2003. Environment and statecraft. Oxford University Press, Oxford, UK. Bennear, L., Stavins, R., 2007. Second-best theory and the use of multiple policy instruments. Environmental \& Resource Economics 37, 111-129.

Bosetti, V., Carraro, C., Duval, R., Sgobbi, A., Tavoni, M., 2009a. The role of R\&D and technology diffusion in climate change mitigation: new perspectives using the WITCH model. OECD Economics Department Working Paper No. 664.

Bosetti, V., Carraro, C., Massetti, E., Tavoni, M., 2008. International energy R\&D spillovers and the economics of greenhouse gas atmospheric stabilization. Energy Economics 30, 2912-2929.

Bosetti, V., Carraro, C., Massetti, E., Sgobbi, A., Tavoni, M., 2009b. Optimal energy investment and R\&D strategies to stabilise greenhouse gas atmospheric concentrations. Resource and Energy Economics 31-2, 123-137.

Carraro, C., Massetti, E., Nicita, L., 2009a. How does climate policy affect technical change? An analysis of the direction and pace of technical progress in a climateeconomy model. The Energy Journal 30 (2), 7-38.

Carraro, C., De Cian, E., Tavoni, M., 2009b. Human capital formation and global warming mitigation: evidence from an integrated assessment model. CESIFO working paper no. 2874, Munich.

Davis, G., Owens, B., 2003. Optimizing the level of renewable electric R\&D expenditures using real options analysis. Energy Policy 31 (15), 1589-1608.
Gerlagh, R., van der Zwaan, B., 2006. Options and instruments for a deep cut in CO2 emissions: Carbon dioxide capture or renewables, taxes or subsidies? Energy Journal 27 (3), 25-48.

Fisher, C., 2008. Emissions pricing, spillovers, and public investment in environmentally friendly technologies. Energy Economics 30 (2), 487-502.

IEA, 2008. Energy technology perspectives 2008. OECD, Paris.

IEA, 2009. World energy outlook 2009. OECD, Paris.

IEA, 2010. Global gaps in clean energy RD\&D. OECD, Paris.

Jaffe, A., Newell, R., Stavins, R., 2005. A tale of two market failures: technology and environmental policy. Ecological Economics 54, 164-174.

Jamasab, T., 2007. Technical change theory and learning curves: patterns of progress in electric generation technologies. The Energy Journal 28 (3).

Nemet, G., Kammen, D., 2007. U.S. energy research and development: declining investment, increasing need, and the feasibility of expansion. Energy Policy 35 (1) 746-755.

Newell, R.G., 2008. International climate technology strategies. Discussion Paper 08-12. Harvard Project on International Climate Agreements, Cambridge, Mass.

Philibert, C., 2003. Technology innovation, development and diffusion. OECD and IEA Information Paper. COM/ENV/EPOC/IEA/SLT(2003)4. International Energy Agency, Paris.

Popp, D., 2002. Induced innovation and energy prices. The American Economic Review 92 (1), 160-180.

Popp, D., 2006. R\&D subsidies and climate policy: is there a 'free lunch'? Climatic Change 77 (3-4), 311-341.

Sandén, B., Azar, C., 2005. Near-term technology policies for long-term climate targets economy - wide versus technology specific approaches. Energy Policy 33, 1557-1576.

Schock, R., et al., 1999. How much is energy research \& development worth as insurance? Annual Review of Energy and the Environment 24, 487-512. 